\title{
Drag reduction by air release promotes fast ascent in jumping emperor penguins - a novel hypothesis
}

\author{
John Davenport ${ }^{1, *}$, Roger N. Hughes ${ }^{2}$, Marc Shorten ${ }^{1}$, Poul S. Larsen ${ }^{3}$ \\ ${ }^{1}$ Department of Zoology, Ecology and Plant Science, University College Cork, Distillery Fields, North Mall, Cork, Ireland \\ ${ }^{2}$ School of Biological Sciences, Bangor University, Deiniol Road, Bangor, Gwynedd LL57 2UW, UK \\ ${ }^{3}$ Department of Mechanical Engineering, Fluid Mechanics Section, Technical University of Denmark, Building 403, \\ 2800 Kgs. Lyngby, Denmark
}

\begin{abstract}
To jump out of water onto sea ice, emperor penguins must achieve sufficient underwater speed to overcome the influence of gravity when they leave the water. The relevant combination of density and kinematic viscosity of air is much lower than for water. Injection of air into boundary layers ('air lubrication') has been used by engineers to speed movement of vehicles (ships, torpedoes) through sea water. Analysis of published and unpublished underwater film leads us to present a hypothesis that free-ranging emperor penguins employ air lubrication in achieving high, probably maximal, underwater speeds (mean \pm SD: $5.3 \pm 1.01 \mathrm{~m} \mathrm{~s}^{-1}$ ), prior to jumps. Here we show evidence that penguins dive to 15 to $20 \mathrm{~m}$ with air in their plumage and that this compressed air is released as the birds subsequently ascend whilst maintaining depressed feathers. Fine bubbles emerge continuously from the entire plumage, forming a smooth layer over the body and generating bubbly wakes behind the penguins. In several hours of film of hundreds of penguins, none were seen to swim rapidly upwards without bubbly wakes. Penguins descend and swim horizontally at about $2 \mathrm{~m} \mathrm{~s}^{-1}$; from simple physical models and calculations presented, we hypothesize that a significant proportion of the enhanced ascent speed is due to air lubrication reducing frictional and form drag, that buoyancy forces alone cannot explain the observed speeds, and that cavitation plays no part in bubble formation.
\end{abstract}

KEY WORDS: Emperor penguins · Air lubrication · Bubbly wakes · Jumping

\section{INTRODUCTION}

Emperor penguins Aptenodytes forsteri Gray are the largest living penguins, standing around $1.2 \mathrm{~m}$ high and weighing 25 to $40 \mathrm{~kg}$ (depending upon gender plus reproductive and nutritional states). They breed and rest on sea ice around Antarctica. As they have short hindlimbs and limited climbing ability, they have to jump from the sea onto sea ice that can vary a great deal in thickness. Their predators include leopard seals Hydrurga leptonyx and killer whales Orca orcinus and it is usually assumed that their ability to jump swiftly and without falling back into the sea is also an effective antipredator adaptation. Emperor penguins exhibit stereotypical responses when entering and leaving the water that are assumed to reflect adaptations to sustained predator presence. When entering the water they usually enter en masse, but reluctantly, with birds often pushing other penguins into the water first. Leaving the water by jumping is also usually accomplished gregariously and at high speed. To jump, an emperor penguin must achieve sufficient underwater speed to overcome the influence of gravity while the kinetic energy of entrained mass is assumed to stay with the water and contribute to splash and surface waves.

Sato et al. (2005) studied emperor penguins, instrumented to provide detailed time records of speed, flipper action and depth during dives and ascents to jump onto the ice surface through small, $1.2 \mathrm{~m}$ diameter 
holes in 2.3 to $2.5 \mathrm{~m}$ thick ice far from the open sea. The above-water heights that they achieved were small ( 0.2 to $0.46 \mathrm{~m})$, but recorded exit speeds rose above the normal $2 \mathrm{~m} \mathrm{~s}^{-1}$ to between 2.5 and $3 \mathrm{~m} \mathrm{~s}^{-1}$ just prior to exit; this correlated well with the velocities required to overcome the effects of gravity for the given heights. Flipper action stopped some distance below the free surface, which was interpreted as implying that buoyancy played a significant role in attaining the higher exit speed (effectively reached in glide mode), a behaviour observed and modelled earlier for king and Adélie penguins (Sato et al. 2002).

The present study is based on close inspection and analysis of a widely-published film of swimming and jumping emperor penguins (BBC 2001), plus unpublished associated film provided by the BBC, which leads us to hypothesize that free-ranging emperor penguins employ drag reduction by air bubble release ('air lubrication') in achieving high speeds prior to jumping from sea water onto ice shelves. To construct a theoretical basis for future experimental testing of our airlubrication hypothesis, we present a model and analysis of the means by which this previously unreported phenomenon could be achieved.

We propose that the air release from the plumage during ascent (as also evidenced at first glance by the pronounced wakes of air bubbles trailing ascending penguins) is believed to be similar to the process of air lubrication studied for engineering purposes. Thus early flat plate studies for turbulent flow showed that frictional drag could be reduced by up to $80 \%$ immediately downstream of microbubble injection and to 'near-100\%' if plates were covered by a thin film of air (McCormick \& Bhattacharryya 1973, p. 15). Increasing air flow reduces the skin friction. For example, to achieve a $60 \%$ reduction in local skin friction by injection of microbubbles in a turbulent boundary layer at a free stream velocity of $4.6 \mathrm{~m} \mathrm{~s}^{-1}$, Madavan et al. (1985, Fig. 13 therein) needed a volume flow of air that was $54 \%$ of the volume flow of water in the boundary layer in the absence of bubbles. This measurement was taken at a distance of about $0.14 \mathrm{~m}$ downstream of the short porous section of wall where injection occurred, but drag reduction appeared to persist for as much as 60 to 70 boundary-layer thicknesses downstream (about 0.52 to $0.61 \mathrm{~m}$ ). Measured turbulence spectra also indicated a reduction of highfrequency shear-stress fluctuations, hence a reduction of the near-wall turbulence, as one cause of drag reduction. It was found that microbubbles had to be present in the boundary layer close to the test surface, having no drag-reducing effect if they were outside the boundary layer (see also Guin et al. 1996 for discussion). A detailed recent plate study at high flow rates (6 to $18 \mathrm{~m} \mathrm{~s}^{-1}$; Sanders et al. 2006) showed that a large void fraction (i.e. high ratio of bubble volume to bubble plus water volume) close to the test plate yielded the greatest reductions in drag, while bubble size was rather less important. However, although reduction in fluid density from water to air-water mixture is believed to be a major factor, this does not explain the whole of the drag reduction achieved (Sanders et al. 2006).

It should also be stressed that most plate studies have focused on the injection of bubbles into the water flow at the upstream end of the plate and been concerned with the degree to which bubbles are effective in downstream drag reduction. This follows from the principal motivation for such studies: the achievement of reduced fuel consumption in large commercial vessels such as oil tankers, in which frictional drag can make up as much as $80 \%$ of total drag (Fukuda et al. 2000), but where air injection over the whole wetted surface is impracticable. Drag reductions of 15 to $40 \%$ and speed increases of $27 \%$ have been achieved in far more modest-sized experimental vessels (though by use of macroscopic air spaces, not by injection of bubbles). A major obstacle to progress has been that propulsors (e.g. ship screws, water jets) must be protected from air bubbles (Matveev 2003).

In another approach relevant to the present study, Fukuda et al. (2000) applied air injection to plates and large ship models that had been painted with a hydrophobic paint. In this case, bubbles coalesced to form thin air films over the painted surfaces; frictional resistance was reduced by $80 \%$ in a flow of $4 \mathrm{~m} \mathrm{~s}^{-1}$ and by $55 \%$ at $8 \mathrm{~m} \mathrm{~s}^{-1}$, which was significantly more than without paint. The reason for a significant drag reduction is readily illustrated qualitatively by considering the frictional drag $F_{\mathrm{d}}$ for the simple cases of a laminar and a turbulent boundary layer over a flat plate of length $L$ and width $B$ (Schlichting 1968, p. 128 and 599 therein):

$$
\begin{aligned}
& F_{\text {d,lam }}=1 / 2 \rho V^{2} L B \times 0.664 \mathrm{Re}^{-1 / 2} \propto V^{3 / 2} \rho v^{1 / 2} \\
& F_{\text {d,tur }}=1 / 2 \rho V^{2} L B \times 0.074 \mathrm{Re}^{-1 / 5} \propto V^{9 / 5} \rho v^{1 / 5}
\end{aligned}
$$

where $V$ is the free stream velocity, $\operatorname{Re}=V L / \nu$ denotes the Reynolds number, $v \equiv \mu / \rho$ the kinematic viscosity, $\mu$ is dynamic viscosity and $\rho$ is density. For a given $V$, the ratio of frictional drag for flow of pure water and pure air at atmospheric pressure and $0^{\circ} \mathrm{C}$ (where the ratio of densities is $1000: 1.3$ and of kinematic viscosities 1.75:13.5) is about 277 for laminar flow and 511 for turbulent flow. These ratios explain qualitatively why the formation of a continuous air film along a flat plate due to coalescence of injected bubbles may give rise to 'near-100\%' reduction of the skin friction, even though such a double boundary layer of air film-driven water flow does not satisfy Eqs. (1) \& (2). 


\section{METHODS}

The published film sequences of emperor penguins (BBC 2001) were collected at Cape Washington, Ross Sea, Antarctica under calm conditions with a flat sea surface. They total 56.04 s, consisting of 1401 fields, $0.04 \mathrm{~s}$ apart, and show penguins ascending rapidly and jumping out of the sea onto the ice shelf. The BBC also supplied unedited, unpublished film collected as part of the film making. This latter film, which showed that at least one leopard seal was present in the area of penguin activity, totalled about $2 \mathrm{~h}$, but most footage was unusable for analysis. However, there were sufficient usable sequences to evaluate downwards and horizontal swimming near the sea surface. Selected sequences from both published and unpublished material were copied to a computer and loaded onto Motion Analysis Tools (The Ottawa Hospital Rehabilitation Centre), a software analytical program that allows frame-byframe study, plus linear and angular measurements. Much of the material could only be considered qualitatively as the camera was either in constant motion (panning), or was directed substantially upwards or downwards, so that birds moved away from or towards the camera. Although flippers were seen to be active in both horizontal and ascent swims, no sequences permitted reliable analysis of flipper action (e.g. beat frequency, angle of incidence). However, there were several sequences that satisfied the following criteria: (1) the background (usually ice shelf) was stationary, indicating a non-moving camera; (2) the camera was close to horizontal; (3) the birds were constantly in focus; (4) if viewed from the dorsal aspect, ascending penguins

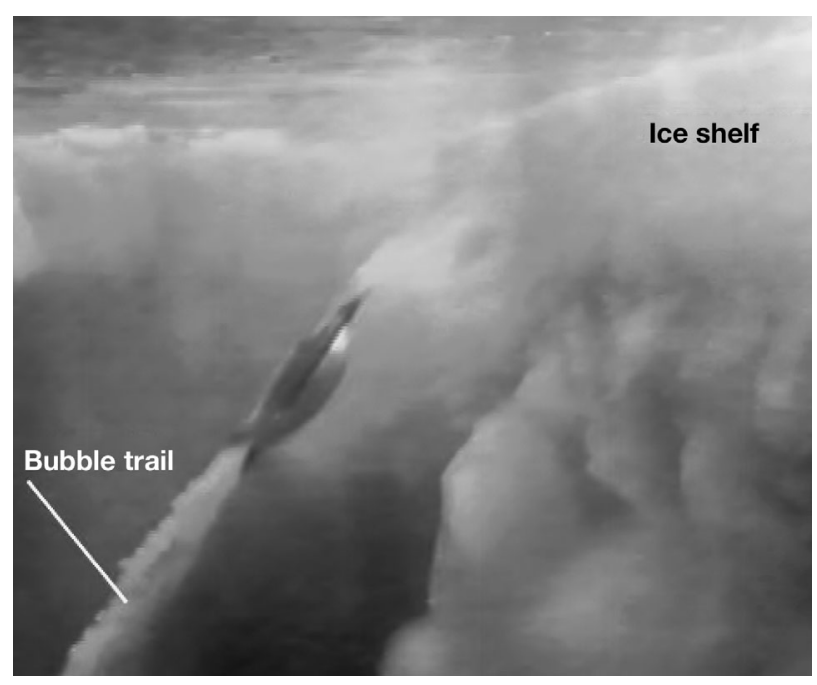

Fig. 1. Aptenodytes forsteri. Ascending emperor penguin approaching sea water surface close to edge of Antarctic ice shelf. Note highly visible trail of air bubbles. From BBC (2001), with permission were at the near-vertical phase of their ascents (so were not moving away from the camera); (5) descending birds, or horizontally-swimming birds were viewed from a completely lateral aspect (i.e. not moving away from or towards the camera); (6) distance between birds and camera was sufficient to minimize parallax problems. In these circumstances, quantitative data were extracted. Distances and speeds for any continuous sequence of fields were calibrated by assuming a standard bird length (bill tip to hindmost visible limit of feet) of $1.25 \mathrm{~m}$ (emperor penguins stand some 1.10 to $1.20 \mathrm{~m}$ high on ice with the beak at right angles to the body axis, but swim with the beak parallel to the body axis). There will inevitably be a linear error of about $\pm 0.05 \mathrm{~m}$ $( \pm 4 \%)$, simply because of the variability of penguin size. The beak tip (readily discernible) was the marker position used in all such sequences.

Several near-surface sequences were available where the quantitative criteria were met, where the birds were in side view, and where the sea surface was visible. In these circumstances, it was possible to establish the angle between the body axis of the ascending/descending penguin and the horizontal sea surface.

\section{RESULTS}

\section{Observations}

The most crucial observation of our study is that emperor penguins swimming upwards to jump out of the water trail long visible wakes of air bubbles (Fig.1). In underwater portions of the published film, 46 different penguins were seen to swim near-vertically upwards at high speed before adopting a rather shallower angle to the horizontal as they jumped through the water surface close to the ice shelf. No birds fell back and all created wakes of air bubbles throughout the ascent. The density of bubbly wakes varied amongst individual penguins, but the wakes remained constant for an individual throughout the upwards swim. There were no signs of the birds exhausting the air supply, and-as expected-wake flows followed the birds as they moved through the water surface. Also, most birds continued to use their flippers throughout the swim to the surface (i.e. there was no glide phase prior to emergence).

A priori there could be 2 possible sources of air that could generate the wakes, the respiratory system or the plumage. Vaporous cavitation could be ruled out because of insufficient speed and the fact that bubbles persisted in the wake. Antarctic fur seals exhale on ascents to avoid shallow water blackout (Hooker et al. 2005), so close-up sequences were inspected to see whether air issued from the beak/nares area; none did. It was clear that air issued from the plumage over most 
of the body, forming a tight-fitting cloud of bubbles (Fig. 2). Close inspection of the bubble clouds showed that bubbles were extremely fine (visible as light blue clouds in which individual bubbles could not be discerned) at the anterior of the penguins' bodies, but became thicker and whiter towards the tail. In most close-up views the cloud was smoothly applied to the penguin body, forming a tube around the tail and hind limbs; coherent structures were visible in the early part of the wake behind the animal, but faded away as the wake bubbles dispersed and rose. Only in one image of a penguin very close to the water surface (Fig. 3) was the bubble cloud disturbed; large bubbles were also visible issuing from the breast/belly region of the individual. Bubble clouds appeared stronger on the dorsal surface of penguins ascending at angles from the vertical, presumably reflecting the tendency of air to rise in the water column (cf. Madavan et al. 1985).

In all underwater sequences, the bulk of the flippers were outside the bubble clouds, so acting against an incompressible medium. Localized signs of dorsal bubble cloud disturbance (posterior to the flippers) as the flippers beat were occasionally visible, while bubble clouds affected the base of the visible right flipper in a penguin filmed close to the sea surface (Fig. 3).

Six fast-ascending penguins trailing bubbly wakes were seen to abort ascents, their paths curving in abrupt near-vertical turns before the penguins descended again. The penguins appeared to be responding to the close proximity of other penguins or the cam-

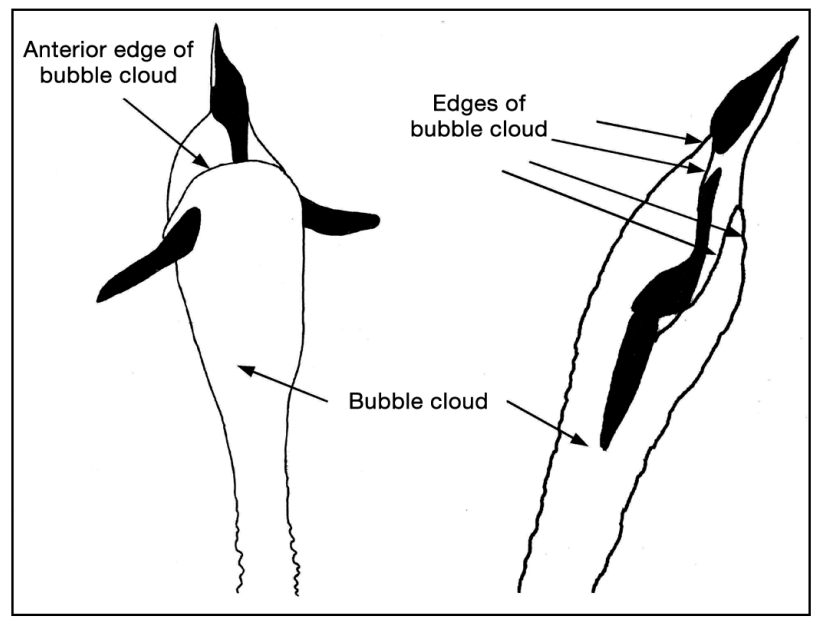

Fig. 2. Aptenodytes forsteri. Images of near-vertically ascending emperor penguins. Note that these drawings, drawn from sequential close-up fields (from BBC 2001) of 2 different penguins, demonstrate that the bubble clouds envelop most of the body and obscure the tail and hind limbs. Note also that the identified anterior edges of the bubble clouds correspond to areas where bright bubbles can be seen against the penguin surface. It is likely (given the close-up image shown in Fig. 3) that less visible bubbles emerge more anteriorly era operative; effectively their ascents were baulked. It was seen that air bubbly wakes continued to issue from the penguins' plumage until after they had completed the turns, but died away completely as the penguins descended. Clearly the bubbly wakes are related to ascents in the water column, not descents. Only one of the aborted ascents could be analyzed quantitatively; before slowing during the abort, the penguin concerned was travelling at $5.8 \mathrm{~m} \mathrm{~s}^{-1}$. This value is within the range of swimming speeds of successfully-ascending penguins (see 'Film analysis'). This reinforces our impression that ascents are not aborted because of inadequate speed, but because of interference.

Although we inspected several hours of film in total, which recorded the movements of several hundred penguins, in no case did we see free-ranging penguins that rapidly ascended without bubble trails, or without active use of their flippers. This strongly suggests that rapid upward swimming without bubbly wakes is very rare (if it ever occurs at all). Some penguins swam upwards (without bubbly wakes) but, although these sequences were not analyzable (camera moving slightly, or birds too close to the camera), they were obviously very slow. The animals were often not even flapping the flippers, simply drifting upwards (presumably because of positive buoyancy) through the last couple of metres of the water column to the surface. Air bubble trails were seen in the case of descending penguins. In almost all cases this occurred as animals left the water surface; the bubbly trails died away within 2 to 3 flipper strokes. There were 2 exceptions, both being penguins that had clearly dived through the

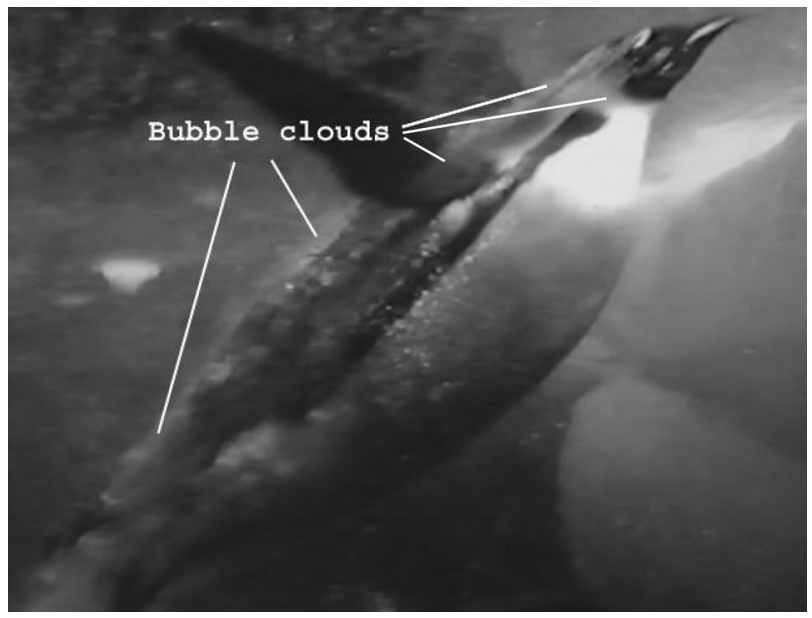

Fig. 3. Aptenodytes forsteri. Image of ascending emperor penguin about to break through water surface. Note fine bubbles emerging from throat plumage and waves in bubble cloud over nape. Note also the bubble cloud visible at the base of right flipper. Large bubbles are visible issuing from flank plumage. Note that no air is issuing from beak or nares. From BBC (2001), with permission 
water surface from the ice shelf (of an unknown height) and trailed bubbles for several metres. One entered at a steep angle and briefly achieved $6.2 \mathrm{~m} \mathrm{~s}^{-1}$, but had slowed to $1.9 \mathrm{~m} \mathrm{~s}^{-1}$ by the time the bubble trail ceased. The other penguin's track could not be analyzed, but the bird concerned entered the water at a shallower angle, soon converted to a very rapid horizontal movement that ended in a glide.

The only example of a long bubbly wake other than during an ascent was seen in a single example of a partially 'porpoising' penguin swimming horizontally. This was seen in the additional footage supplied by the $\mathrm{BBC}$, but the cameraman panned the camera, so we could not analyze the footage (i.e. we could not estimate the speed, though it was clearly quite rapid). However, the penguin (which was not jumping entirely out of water, but following an undulating path during parts of which the dorsal section of the body was emersed), trailed bubbles throughout the sinusoidal swimming path, presumably because the plumage was loading with air each time the dorsum emerged from water. In dolphins and penguins, porpoising has been modelled as a method of intermittent locomotion whereby animals reduce their energetic expenditure at high speeds by capitalizing on short periods of unpowered movement through the air (Au \& Weihs 1980). Weihs (2002) has recently revisited the topic of porpoising, but all of the emphasis has been upon reconciling the high energy cost of jumping out of water with the much reduced drag when in air. No-one has previously reported bubbly wakes during the underwater phases of porpoising in penguins, but they might conceivably be energetically beneficial.

\section{Film analysis}

Quantitative analysis of appropriate parts of the film, assuming a standard bird length (tip of beak to hindmost foot) of $1.25 \mathrm{~m}$, showed swimming speeds during bubble trail ascents $(\mathrm{n}=10$ different penguins; all recorded when camera was still) as follows: range 3.8 to $6.1 \mathrm{~m} \mathrm{~s}^{-1}$, mean $5.3 \mathrm{~m} \mathrm{~s}^{-1}$ (SD $1.01 \mathrm{~m} \mathrm{~s}^{-1}$ ). The mean ascending speed corresponds to 4.3 body lengths $\mathrm{s}^{-1}$. The mean final angle of ascent to the horizontal before jumping through the water surface $(\mathrm{n}=6)$ was $60^{\circ}$ $\left(\mathrm{SD} 8^{\circ}\right)$. Swimming speeds of descending penguins $(\mathrm{n}=$ 10) were as follows: range 1.3 to $2.8 \mathrm{~m} \mathrm{~s}^{-1}$, mean $1.9 \mathrm{~m}$ $\mathrm{s}^{-1}$ (SD $\left.0.49 \mathrm{~m} \mathrm{~s}^{-1}\right)$. The mean descending speed corresponds to 1.5 body lengths $\mathrm{s}^{-1}$. Mean angle of descent $(\mathrm{n}=10)$ to the horizontal was $41^{\circ}\left(\mathrm{SD} 9^{\circ}\right)$. Horizontal swimming speeds $(\mathrm{n}=5)$ were: range 1.2 to $2.7 \mathrm{~m} \mathrm{~s}^{-1}$, mean $1.7 \mathrm{~m} \mathrm{~s}^{-1}$ (SD $0.57 \mathrm{~m} \mathrm{~s}^{-1}$ ). The mean horizontal speed corresponds to 1.4 body lengths $\mathrm{s}^{-1}$. The variability of these data is similar to that observed by Kooyman et al. (1992), who used electro-mechanical data loggers to measure swimming speed. One-way analysis of variance (ANOVA) showed that there were highly significant differences amongst the ascending, descending and horizontal swimming speeds $(p<0.0005)$. Post hoc Tukey analysis showed that the descending and horizontal speeds were not significantly different from each other ( $p>0.05)$, but that the penguins ascending with bubble trails travelled far more quickly, reaching a mean of 2.8 times the descending speed.

It was difficult to determine the depth at which bubble trail ascents started. No fixed camera sequences were available, nor was there a complete panned sequence from appearance of the wake to jumping through the sea surface. However, in 1 panned sequence, white wakes could be followed until the sequence ended about $3.2 \mathrm{~m}$ below the water surface. This sequence lasted $2.48 \mathrm{~s}$, implying that the wakes started at a depth of about $16 \mathrm{~m}$ on the assumption that penguins moved vertically at $5.3 \mathrm{~m} \mathrm{~s}^{-1}$.

In 4 jumping sequences, filmed above water at the ice edge on a different occasion and at a different location, it was possible to estimate the maximum height (of the approximate penguin centre of gravity) above the water surface achieved during jumps out of water as being 1.12 to $1.78 \mathrm{~m}$. All heights substantially exceed those recorded by Sato et al. (2005) in emperor penguins jumping through ice holes. Given the mean emergence angle $(\beta)$ of $60^{\circ}$ and mean emergence velocity $\left(V_{0}\right)$ of $5.3 \mathrm{~m} \mathrm{~s}^{-1}$ recorded in the present study, the maximal height $\left(h_{\max }\right)$ of the jumping trajectory, ignoring drag, is calculated from the equation of motion, giving $h_{\max }=h_{0}+V_{0}^{2} \sin ^{2} \alpha / 2 g=1.07 \mathrm{~m}$ (where $h_{0}$ is assumed to be zero and $g$ is the acceleration due to gravity), which agrees with observations of around $1 \mathrm{~m}$ for most jumping penguins. Jumps as high as 1.7 to $1.8 \mathrm{~m}$ agree well with a few observed high velocities, up to $8.2 \mathrm{~m} \mathrm{~s}^{-1}$, just before completely leaving the water. It is likely that some acceleration occurs as the forepart of the body is in air, while the propulsive flippers are still acting against incompressible water (cf. flying fish; Davenport 1994).

\section{Air release during ascent}

Before jumping out of the water onto ice, the penguins swim at the surface and then dive on inspiration (Kooyman et al. 1971). We believe they dive with plenty of air in the plumage, with erected feathers making room for an air layer about $25 \mathrm{~mm}$ thick (following Du et al. 2007). Kooyman et al. (1971) described the grooming behaviour by which surface swimming emperor penguins load their plumage with air and we confirmed this by observation of parts of the un- 
published BBC film. They subsequently dive to $\sim 15$ to $20 \mathrm{~m}$ (by which depth the air volume will have decreased by a substantial amount, see Eq. 3). During the dive, or when achieving that depth, they depress the feathers (to fix the plumage volume at the new, decreased level). When the birds swim quickly upwards, the decompressing air will flow out by virtue of the available fixed plumage volume being substantially less than the initial volume. Plumage consists of a fine, multi-layered mesh over the whole of the body surface comparable to a porous medium with an estimated pore size of $<20 \mu \mathrm{m}$ ( $\mathrm{Du}$ et al. 2007), so the expanding air will automatically issue as small bubbles. This arrangement resembles the flat-plate experiments of Sanders et al. (2006), who used a $40 \mu \mathrm{m}$ pore size sintered stainless steel strip for microbubble air injection. The 'active' part of the process consists solely of maintenance of depressed feathers during the nearvertical phase of the ascent in order to regulate expulsion of air driven by decompression. As bubbles continue to enter the boundary layer along the plumage, they are swept downstream and move outwards, thus increasing the void fraction in the boundary layer downstream to finally leave in the wake behind the bird; or they coalesce with other bubbles to form rather large bubbles at the outer edge of the boundary layer (see Fig. 3). It is likely that a large number of small bubbles may still remain within the boundary layer, as can be seen by calculating a typical turbulent boundary layer thickness $\delta$ in liquid flow at a distance, say $x$ $=0.5 \mathrm{~m}$ downstream from the leading edge of a flat plate, estimated from Schlichting (1968, p. 599) as $\delta=$ $0.37(\mathrm{xV} / \mathrm{v})^{-0.2}=0.37 \times 0.5 \times\left(0.5 \times 5.3 / 10^{-6}\right)^{-0.2}=0.010 \mathrm{~m}$ $=10 \mathrm{~mm}$, increasing to $17 \mathrm{~mm}$ at $x=1.0 \mathrm{~m}$. For this estimate, we have used a free stream velocity of $V=5.3 \mathrm{~m}$ $\mathrm{s}^{-1}$ and a kinematic viscosity of $\mathrm{v}=10^{-6} \mathrm{~m}^{2} \mathrm{~s}^{-1}$. Although the growth of the boundary layer on a body like that of a penguin is different from that of a flat plate, the order of magnitude of thickness is similar.

As an aid to understanding the strategy used by penguins during ascent, 2 alternative simple physical models have been examined for estimating the rate of air release during ascents. To this end, assume the volume of entrapped air can be represented by a layer of initial thickness $s_{0}$ of pure air at atmospheric pressure (i.e. an absolute pressure of $\approx 10 \mathrm{~m}$ water column). As long as there is no release, the thickness of air layer $s$ varies with depth $d$ below the free surface as:

$$
s=s_{0}(1+d / 10)^{-1}
$$

so that at $d_{1}=15 \mathrm{~m}$, for example, we have $40 \%$ of the initial thickness: $s_{1}=0.4 s_{0}$. Here we have used the ideal gas law, assuming isothermal conditions, so the product of absolute pressure and volume (or thickness $s$ over a fixed area) remains constant. In reality, condi- tions may not be isothermal as weather-dependent Antarctic air temperatures can be significantly lower or higher than that of sea water in thermal equilibrium with sea ice $\left(-1.9^{\circ} \mathrm{C}\right)$. However, even a $25^{\circ} \mathrm{C}$ difference (probably the maximum likely) will have relatively small effects on entrapped air volume, so no attempt has been made to take this into account. Also, we can safely ignore the varying static pressure associated with the change of free stream velocity along the surface of the penguin. At the front stagnation point, the pressure is higher than the local hydrostatic pressure (by $1.4 \mathrm{~m}$ water column at an onset flow of $5.3 \mathrm{~m} \mathrm{~s}^{-1}$ ) while it is lower (by an estimated $0.7 \mathrm{~m}$ water column) near the head and (by no more than $0.3 \mathrm{~m}$ water column) over the rest of the body. In terms of hydrostatic pressure change with depth, the variations mentioned are comparable with the variation over length of a vertically oriented penguin. One may now consider 2 strategies: (1) the thickness of air layer in the plumage remains constant at the value $s_{1}$ during ascent while air is released due to decompression according to the isothermal volume increase of air with decreasing depth; or (2) the thickness $s$ of the air layer decreases during ascent in a controlled way (by decompression and depression of feathers) so as to maintain a constant rate of air outflow per unit area (a velocity denoted $u$ ) at any depth. Model (1) would imply that most of the mass of entrapped air is expended at great depths, leaving little as the surface is approached, so that the bubbly wake should diminish with decreasing depth. Since observations show all bubbly wakes to be of unchanged strength during observable ascents, we favour model (2).

In this case, the air-outflow velocity $u$ is maintained constant by the combined action of decompression and depression of feathers such that the thickness of the generated bubble layer (and ensuing drag reduction) should be unchanged during the ascent. Here the depression of feathers may help overcome the pressure drop associated with the flow of air through the fine mesh of feathers. The resulting drag reduction is assumed to depend only on the volume of air bubbles formed, not the air pressure, which varies with depth. We now calculate how the air-layer thickness $s$ of entrapped air varies during vertical ascent with constant velocity $V$, starting at time $t=0$ with the value $s_{1}$ at depth $d_{1}$ as before. Without air release, $s$ varies as given by Eq. (3), where $d=d_{1}-V t$, but with constant air release $u$ it becomes:

$$
s=s_{0}\left[1+\left(d_{1}-V t\right) / 10\right]^{-1}-u t
$$

Introducing the time of ascent $t_{\mathrm{a}}=d_{1} / V$ and $t_{\mathrm{a}} u=k s_{0}$, where $k$ denotes the fraction of initially entrapped air that has been used up when arriving at the sea surface, Eq. (4) becomes: 


$$
s / s_{0}=\left[1+\left(d_{1} / 10\right)\left(1-t / t_{\mathrm{a}}\right)\right]^{-1}-k t / t_{\mathrm{a}}
$$

or in terms of $s / s_{0}$ versus depth $d$ :

$$
s / s_{0}=(1+d / 10)^{-1}-k\left(1-d / d_{1}\right)
$$

Fig. 4 shows how the air-layer thickness decreases with depth during ascent from initial depths of $d_{1}=10$, 12,15 and $20 \mathrm{~m}$ according to Eq. (5) for $k=1$, which corresponds to all air being used up. Only positive values of $s / s_{0}$ have physical meaning, so the maximal feasible initial depth is about $10 \mathrm{~m}$ if air release were to continue until the free surface has been reached. Starting at a depth of $15 \mathrm{~m}$, however, air release would terminate at a depth of about $5 \mathrm{~m}$. It is clearly costly to start releasing air at great depths because, for a given layer thickness, relatively more mass of air is expended due to its compression. However, starting from greater depths than $10 \mathrm{~m}$ would be possible by the use of alternative strategies, such as intermittent release spatially along body and/or in time, or by reducing $u$ through values of $k<1$. Fig. 5 shows, for $d_{1}=15 \mathrm{~m}$, how decreasing the value of $k$ ensures that $s$ remains positive during full ascent, but then not all of the available air becomes useful. Considering a reference case $\left(k=0.9, L=1 \mathrm{~m}, s_{0}=25 \mathrm{~mm}\right.$ and $\left.d_{1}=15 \mathrm{~m}\right)$, the air-outflow velocity becomes $u=k s_{0} V / d_{1}$ $=0.008 \mathrm{~m} \mathrm{~s}^{-1}$ and $90 \%$ of the available air becomes useful. By comparison, it can be shown that only $60 \%$ of air is useful in the case of model (1).

\section{Thickness of bubble boundary layer}

Next, with a few more assumptions, it is possible to estimate the thickness $\delta$ of the released air layer (evidently the air appears as bubbles, but for conservation of mass it is simpler to think in terms of a layer of pure

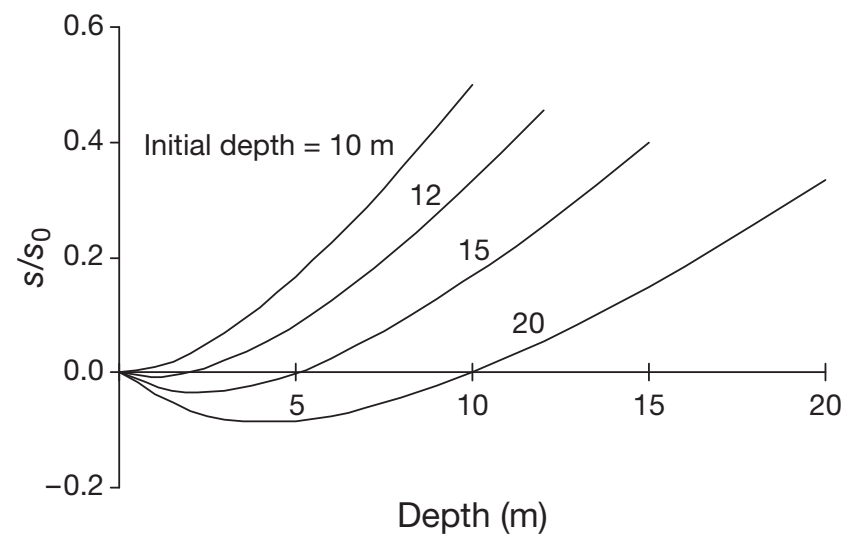

Fig. 4. Aptenodytes forsteri. Calculated relative air layer thickness $\left(s / s_{0}\right)$ versus depth $(d$, in $\mathrm{m})$ during ascent with constant velocity $\left(V=5.3 \mathrm{~m} \mathrm{~s}^{-1}\right)$ and constant air release and all entrapped air used up $(k=1)$, showing effect of increasing initial depth

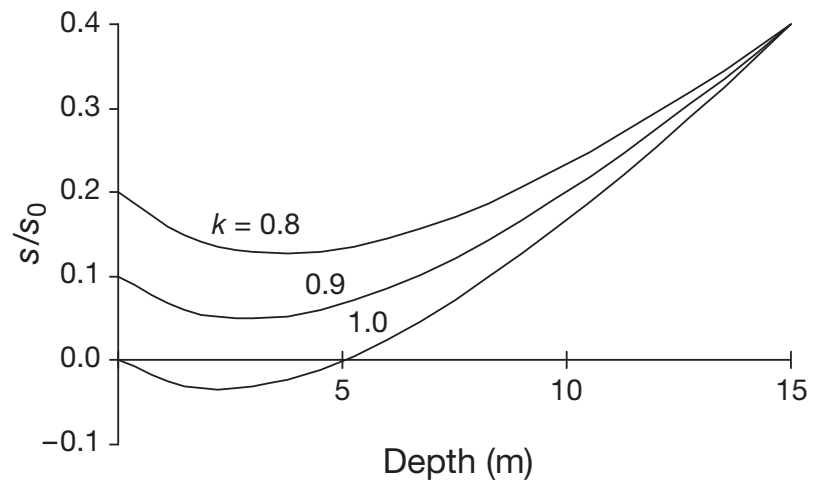

Fig. 5. Aptenodytes forsteri. Calculated relative air layer thickness $\left(s / s_{0}\right)$ versus depth $(d$, in $\mathrm{m})$ during ascent from $d_{1}=15 \mathrm{~m}$ with constant velocity $\left(V=5.3 \mathrm{~m} \mathrm{~s}^{-1}\right)$ and constant air release, showing effect of decreasing $k$

air, which later may be interpreted as a bubble layer of some void fraction). When air is released at the rate $u$ along a section of length $L$ of a cylindrical body, $\delta$ would increase with distance $x$ from the upstream point $(x=0)$ as given by the equation of continuity, $\mathrm{d}\left(V_{\mathrm{BL}} \delta\right) / \mathrm{d} x=u$, subject to the boundary condition $\delta(0)$ $=0$, where $V_{\mathrm{BL}}$ denotes a representative velocity of the air in the boundary layer. Taking $V_{\mathrm{BL}}$ to be one-half of the constant swimming velocity, $V_{\mathrm{BL}}=1 / 2 V$, the linear increase of $\delta$ would give a mean value over length $L$ of $\delta_{\text {mean }}=1 / 2 \operatorname{Lu} /(1 / 2 V)=L u / V$.

For our model, $\delta_{\text {mean }}$ would be constant during ascent and (using $t_{\mathrm{a}} u=k s_{0}$ and $t_{\mathrm{a}}=d_{1} / V$ ), given by $\delta_{\text {mean }}=$ $k L s_{0} / d_{1}$. For the reference case $\left(k=0.9, L=1 \mathrm{~m}, s_{0}=\right.$ $25 \mathrm{~mm}$ and $d_{1}=15 \mathrm{~m}$ ) this gives $\delta_{\text {mean }}=1.5 \mathrm{~mm}$ and a mean bubble layer (at $10 \%$ void) of $15 \mathrm{~mm}$, increasing to $30 \mathrm{~mm}$ at the tail end, during the whole period of ascent. Due to the body shape of a penguin, the free stream velocity will be somewhat higher than the swimming velocity, but aside from the head region (where local high velocities are incurred), not by more than 5 to $6 \%$, which would imply a slightly thinner bubble layer. On the other hand, bubbles probably move at velocities less than the assumed $1 / 2 V$ and thus tend to lead to a thicker bubble layer.

Measurements made with Motion Analysis Tools from a close-up frame of a penguin near to the sea surface suggest fine bubble layers of thickness of $\sim 20 \mathrm{~mm}$, at locations 0.28 and $0.68 \mathrm{~m}$ from the tip of beak in the dorsal region (observations could not be collected from the ventral region). However, because the bird was travelling at around $60^{\circ}$ to the horizontal at this time, it is likely that the tendency of bubbles to rise will have led to greater thicknesses of bubbles being evident in the dorsal than the ventral areas, so it is probable that $20 \mathrm{~mm}$ is an overestimate. This (distinctly limited) observation nevertheless shows an order of magnitude agreement with the model results. 


\section{Propulsive force and power}

At a steady, horizontal swimming velocity $V$ (i.e. free stream velocity), the propulsive force $F_{\mathrm{P}}$ equals the drag force:

$$
F_{\mathrm{d}}=C_{\mathrm{d}} A \frac{1}{2} \rho V^{2}
$$

where $C_{\mathrm{d}}$ denotes the drag coefficient, $A$ a characteristic area of the body and $\rho$ the density of water, and the expended power is:

$$
P=F_{\mathrm{P}} V=C_{\mathrm{d}} A \frac{1}{2} \rho V^{3}
$$

To attain a swimming velocity of about $5.3 \mathrm{~m} \mathrm{~s}^{-1}$, a factor of 5.3/2 $=2.65$ times the normal cruising speed of $2 \mathrm{~m} \mathrm{~s}^{-1}$, would imply increases in propulsive force and power by factors $2.65^{2}=7.02$ and $2.65^{3}=18.6$, respectively, assuming an unchanged $C_{\mathrm{d}}$. Such increases are unlikely, even for the short duration $(\sim 3 \mathrm{~s})$ of ascent. However, if bubble release from the plumage causes a reduction of the product $C_{\mathrm{d}} \rho$ by a factor of 18.6 (i.e. to about $5.4 \%$ of the single-phase liquid flow drag), the expended power would be unchanged from that at the normal cruising speed of $2 \mathrm{~m} \mathrm{~s}^{-1}$, and the required propulsive force would be correspondingly reduced. However, it is likely that, during ascents, penguins expend more power and are aided by buoyancy, so that less drag reduction would be required to achieve the observed high speeds.

The total drag on a streamlined body such as a penguin is the sum of frictional drag in the boundary layer along the surface and form drag associated with the pressure distribution around the body. Form drag may constitute as much as $20 \%$ or more of the total drag (Schlichting 1968, Figs. 25.4 and 25.5 for a streamlined body of length to diameter ratio of 4), so even if skin friction were reduced to a negligible amount due to bubbles in the boundary layer and/or coalescence of bubbles to form patches of air film along the plumage surface, there would still remain a sizable contribution from form drag, unless this was also affected by air release.

To examine this problem we consider the classical analysis used in calculating total drag on a body from experimental data of wake measurements (e.g. Schlichting 1968, p. 166 therein). Fig. 6 shows a cylindrical control volume (dashed outline) surrounding the body subject to an incoming flow of uniform velocity $V_{1}$ and liquid density $\rho$ over area $A_{1}$, leaving the body partly along the cylindrical side of area $A_{3}$ (to satisfy continuity) and partly downstream over area $A_{2}$ with reduced velocity and density in the wake (stippled area) due to the air release $Q_{\mathrm{a}}=u A_{\mathrm{p}}$ of density $\rho_{\mathrm{a}}$. Assuming the control volume surface to be far enough from the body that pressure is uniform, the conservation of mass and balance of momentum become: and:

$$
\rho Q_{3}=\rho_{\mathrm{a}} Q_{\mathrm{a}}+\int \rho V_{1} d A_{1}-\int \rho_{2} V_{2} d A_{2}
$$

$$
F_{\mathrm{d}}=\int \rho V_{1}^{2} d A_{1}-\int \rho_{2} V_{2}^{2} d A_{2}-\rho Q_{3} V_{1}
$$

or, after elimination of $Q_{3}$ between these equations

$$
F_{\mathrm{d}}=\int \rho\left(1-\alpha_{2}\right) V_{2}\left(V_{1}-V_{2}\right) d A_{2}-\rho_{\mathrm{a}} Q_{\mathrm{a}} V_{1}
$$

where the mixture density has been approximated by $\rho_{2}=\rho_{a} \alpha_{2}+\rho\left(1-\alpha_{2}\right) \approx \rho\left(1-\alpha_{2}\right)$, and where void fraction $\alpha_{2}$ varies across the area $A_{2}$.

Although total drag can only be evaluated from Eq. (8) if detailed data from wake measurements are available, this equation suggests that both skin friction and form drag are affected by air release. The difference between the cases of air release with bubbly flow wake and no air release with pure liquid flow $\left(\alpha_{2}=0\right.$ and $Q_{\mathrm{a}}=0$ ) is to be found in the distribution over $A_{2}$ of velocity $V_{2}$ and void fraction $\alpha_{2}$ since the last term in Eq. (8) is negligible. Increasing air release will increase $\alpha_{2}$ and increase $V_{2}$ as bubbles in the wake are being accelerated by the liquid flow, both contributions that will reduce $F_{\mathrm{d}}$ as compared to the case of no air release hence increase the drag reduction.

\section{Required drag reduction}

To determine the required drag reduction to achieve the observed high ascent speeds, we estimate the magnitude of the buoyancy force, the propulsive force and propulsive power. During normal cruising manoeuvres near the surface, penguins appear to be only slightly positively buoyant, judging by the slow rise of penguins not flapping their flippers. They are evidently quite close to neutral buoyancy.

However, prior to dive and subsequent ascent to jump, we assume the penguin fills its plumage with air

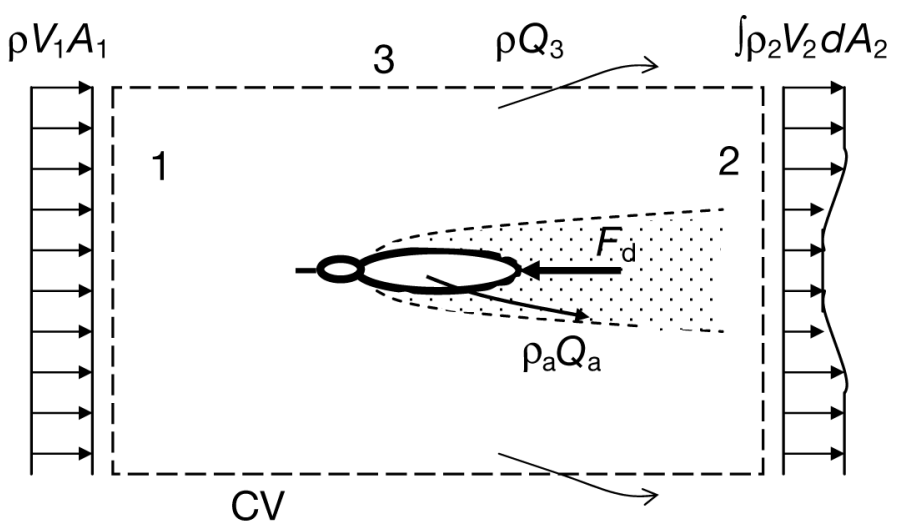

Fig. 6. Aptenodytes forsteri. Control volume (CV) around body to express drag force $F_{\mathrm{d}}$ in terms of momentum change of inflow (1) to outflows (2) and for (3) body with air release $Q_{a}$ generating the bubbly boundary layer and wake (stippled). See 'Results: Propulsive force and power' for further explanation 
at the sea surface and inspires to fill its respiratory system with air. Sato et al. (2002) state that king and Adélie penguins always dive on inspiration; there is no reason to believe that emperor penguins differ in this respect. As in the previous analysis, the air-layer thickness is taken to be $s_{0}=25 \mathrm{~mm}$ over surface area $A=$ $0.6 \mathrm{~m}^{2}$, i.e. an air volume of $15 \mathrm{l}$, and the air volume of the respiratory system is taken to be at most $25 \times 0.1=$ 2.51 for a $25 \mathrm{~kg}$ emperor penguin at an estimated 100 to $200 \mathrm{ml} \mathrm{kg} \mathrm{kg}^{-1}$ according to Sato et al. (2002, Table 2 therein for king and Adélie penguins). Denoting by $g$ the acceleration of gravity, the associated buoyancy force at the sea surface is:

$$
\begin{aligned}
F_{\mathrm{b}}= & \left(\rho-\rho_{\mathrm{a}}\right) \times V \mathrm{Vol}_{\text {air }} \times g \approx 1000 \times(0.015+0.0025) \\
& \times 9.81=172 \mathrm{~N}
\end{aligned}
$$

This significant force corresponds to about $70 \%$ of the weight. As the penguin dives to depth $d$, the air is compressed so the volume of air and hence the buoyancy force $F_{\mathrm{b}}$, decreases as $s$ according to Eq. (3):

$$
s=s_{0}(1+\mathrm{d} / 10)^{-1}
$$

The air density $\rho_{\mathrm{a}}$ increases inversely with respect to $s$ according to the ideal gas law for isothermal conditions, but the approximation $\rho \gg \rho_{a}$ is still reasonable for the depths in question. At depth $d_{1}=15 \mathrm{~m}$, for example, we have $40 \%$ of the initial thickness, $s_{1}=0.4 s_{0}$ and a buoyancy force of about $F_{\mathrm{b}, 1}=69 \mathrm{~N}$ if no air has been released.

First, assuming no air release during ascent (the hypothetical case of a fast ascending penguin not showing bubbly trails) the effect of buoyancy on attainable speed can be evaluated as follows. For steady, horizontal swimming the propulsive force $F_{\mathrm{p}}$ and propulsive power $P_{\mathrm{P}}$ may be evaluated at normal cruising speed by using the established typical values of drag coefficient of $C_{\mathrm{d}}=0.02$ to 0.04 (Hirata \& Kawai 2001) based on surface (wetted) area for streamlined bodies of revolution. The lowest drag occurs at a length to diameter ratio of about 4.5, which is close to that of the emperor penguin (about 3.4). Hence at $V_{0}=2 \mathrm{~m} \mathrm{~s}^{-1}$,

$$
\begin{aligned}
& F_{\mathrm{P}, 0}=F_{\mathrm{d}, 0}=0.02 \times 0.6 \times 1 / 2 \times 1000 \times 2^{2}=24 \mathrm{~N} \\
& P_{\mathrm{P}, 0}=F_{\mathrm{P}, 0} V_{0}=48 \mathrm{~W}
\end{aligned}
$$

The estimate of $C_{\mathrm{d}}=0.02$ is assumed to include frictional drag as well as form drag and induced drag. Due to observed flipper action, we assume the propulsive power to be at least the same during ascent as during cruising, except that there will now be an additional buoyancy-driven propulsive power, $P_{\mathrm{b}}=F_{\mathrm{b}} V$, where $F_{\mathrm{b}}$ is the buoyancy force (assuming a vertical ascent). For a trajectory forming the angle $\theta$ with the vertical it will be smaller by the factor $\cos \theta$.

Equating total propulsive power $P$ to drag at the new velocity $V_{1}$ at depth $d_{1}$ gives:

$$
P=P_{\mathrm{b}}+P_{\mathrm{P}, 0}=F_{\mathrm{b}, 1} V_{1}+P_{\mathrm{P}, 0}=C_{\mathrm{d}} A 1 / 2 \rho V_{1}^{3}
$$

Using $F_{\mathrm{b}, 1}=69 \mathrm{~N}$ and $P_{\mathrm{P}, 0}$ from Eq. (9) in (12) gives $V_{1}=3.70 \mathrm{~m} \mathrm{~s}^{-1}$ at depth $d_{1}=15 \mathrm{~m}$. Similarly, using $F_{\mathrm{b}, 0}=$ 172 gives $V_{0}=5.49 \mathrm{~m} \mathrm{~s}^{-1}$ at depth $d_{0}=0 \mathrm{~m}$.

Within the assumptions made, we conclude that buoyancy could theoretically help to increase the velocity during ascent from about $3.8 \mathrm{~m} \mathrm{~s}^{-1}$ at depth $15 \mathrm{~m}$ to about $5.5 \mathrm{~m} \mathrm{~s}^{-1}$ when the free surface is reached, but only if all air remained within the plumage throughout the ascent (which it clearly does not). However, this is still less than the highest observed emergence speeds $\left(8 \mathrm{~m} \mathrm{~s}^{-1}\right)$. We may therefore again conclude that drag reduction due to the release of air bubbles must be involved in the real situation.

Second, for the actual case of air release from the plumage during ascent with an estimated constant airoutflow velocity $u=0.008 \mathrm{~m} \mathrm{~s}^{-1}$, optimally the air layer thickness would then decrease from $40 \%$ of the initial thickness at depth $d_{1}=15 \mathrm{~m}$ to about $10 \%$ as the free surface is reached (Fig. 5, case of $k=0.9$ ). It follows that the buoyancy force would decrease from $69 \mathrm{~N}$ to about $39.2 \mathrm{~N}$ during the ascent (still assuming $2.5 \mathrm{l}$ air in the respiratory system). For unchanged propulsive power, again using Eq. (12), the maximal attainable velocity would decrease rather than increase during ascent, from 3.70 to $3.03 \mathrm{~m} \mathrm{~s}^{-1}$. To reach the observed average velocity of $5.3 \mathrm{~m} \mathrm{~s}^{-1}$ would require an increase in propulsive power from $48 \mathrm{~W}$ to $685 \mathrm{~W}$, a factor of more than 14 times the power for the normal swimming velocity of $2 \mathrm{~m} \mathrm{~s}^{-1}$. Although buoyancy plays a non-negligible role, its effects are insufficient to explain the observed velocities, and therefore there must be a substantial contribution from drag reduction due to air release during ascent to achieve the observed velocities of the order of $5.3 \mathrm{~m} \mathrm{~s}^{-1}$ or more.

The required drag reduction to attain the observed velocities of ascent can be evaluated as follows. For the actual case of 2.51 air in the respiratory system and air release, leaving air layers of $40 \%$ and $10 \%$ of the initial thickness $s_{0}$, corresponding to depth $d_{1}=15 \mathrm{~m}$ and near the surface, respectively, we set $V_{1}=5.3 \mathrm{~m} \mathrm{~s}^{-1}$ in Eq. (12) and calculate the required reduced value of drag coefficient $C_{\mathrm{d}, \mathrm{r}}$ to obtain the value of required reduced drag ratio as $C_{\mathrm{d}, \mathrm{r}} / C_{\mathrm{d}}$. Results for the estimated normal propulsive power of $48 \mathrm{~W}$ and twice this value are shown in Table 1. These results show that not much is gained by doubling the propulsion power and that more than $70 \%$ drag reduction is needed for the considered average velocity of $5.3 \mathrm{~m} \mathrm{~s}^{-1}$, and considerably more for the higher velocities observed. Some approximate (unpublished) calculations of a bubble boundary layer on a flat plate (validated against experimental data of Madavan et al. 1985) have shown that a uniform air release of $u=0.008 \mathrm{~m} \mathrm{~s}^{-1}$ can provide no 
Table 1. Aptenodytes forsteri. Drag reduction required to achieve the observed mean velocity of $5.3 \mathrm{~m} \mathrm{~s}^{-1}$ at depth $15 \mathrm{~m}$ (relative air-layer thickness, $s / s_{0}=0.40$ ) and near the surface $\left(s / s_{0}=0.10\right)$ at $(\mathrm{A})$ normal power and (B) twice normal power. $C_{\mathrm{d}, \mathrm{r}}$ is the required reduced drag coefficient; $C_{\mathrm{d}}(=0.02)$ that of no drag reduction.

\begin{tabular}{|lccc|}
\hline Propulsive power & $\begin{array}{c}\text { Air-layer } \\
s / s_{0}(\%)\end{array}$ & $C_{\mathrm{d}, \mathrm{r}} / C_{\mathrm{d}}$ & $\begin{array}{c}\text { Drag } \\
\text { reduction (\%) }\end{array}$ \\
\hline A) $48 \mathrm{~W}$ & 40 & 0.463 & 54 \\
& 10 & 0.286 & 71 \\
B) $96 \mathrm{~W}$ & 40 & 0.517 & 48 \\
& 10 & 0.340 & 66 \\
\hline
\end{tabular}

more than about $14 \%$ reduction of the frictional drag, which suggests that coalescence of bubbles to form patches of air film and/or a reduction of form drag are likely to account for the remaining reduction.

\section{Cavitation}

It might be suggested that bubble formation around the penguin is a result of cavitation. To achieve cavitation, the local static pressure should decrease to values at or below the vapour pressure of water at the prevailing temperature, $p_{\text {sat }}(T)$. For pure water, $p_{\text {sat }}=$ $0.611 \mathrm{kPa}$ at $0.01^{\circ} \mathrm{C}$, but is slightly lower for seawater. Assuming normal atmospheric pressure at sea level $(101.3 \mathrm{kPa})$ the static pressure at a depth of $1 \mathrm{~m}$, for example, would be higher by $9.81 \mathrm{kPa}$, so the pressure lowering required to achieve cavitation is of the order of $\Delta p_{\mathrm{c}} \approx 110 \mathrm{kPa}$. For a blunt body moving through water at velocity $V_{\mathrm{S}}$, the lowest pressure occurs near the location of greatest diameter, where the highest velocity $V_{C}$ is attained. The pressure lowering at this point may be calculated from the Bernoulli equation, which is valid outside the viscous boundary layer:

$$
\Delta p_{\mathrm{c}}=1 / 2 \rho V_{\mathrm{S}}^{2}\left[\left(V_{\mathrm{C}} / V_{\mathrm{S}}\right)^{2}-1\right]
$$

We may use Eq. (13) to calculate the minimal swimming velocity $V_{\mathrm{S}}$ that gives cavitation once the pressure lowering $\Delta p_{\mathrm{c}}$ and the shape factor $\left[\left(V_{\mathrm{C}} / V_{\mathrm{S}}\right)^{2}-1\right]$ have been specified. Sample values of the latter from potential flow theory are: 3 for cylinder in cross flow, 1.25 for flow past sphere, 0.37 for flow past streamline body of revolution (18\% thickness), and 0.44 for flow past a model of an approximate, axisymmetric penguin, where the 3 first values are from Schlichting (1968, p. 21-22), while the fourth value was calculated numerically from a distribution of singularities giving an axisymmetric body of approximately the shape of an emperor penguin. Using a conservative value of 0.5 gives $V_{\mathrm{S}}=[2 \times 110000 /(1000 \times 0.5)]^{1 / 2}=21 \mathrm{~m} \mathrm{~s}^{-1}$.
This example shows that it is highly unlikely that cavitation could occur, given that the mean ascent swimming velocity inferred from the video records is about $V_{\mathrm{S}}=5.3 \mathrm{~m} \mathrm{~s}^{-1}$ and that the highest values do not exceed about $8 \mathrm{~m} \mathrm{~s}^{-1}$. Also, bubbles are observed at depths exceeding $1 \mathrm{~m}$, and a non-gaseous cavitation bubble would quickly collapse once it had moved to positions where the pressure exceeds that of cavitation. The observation of a wake filled with bubbles far behind the penguin is proof of bubbles being filled with gas and not by water vapour.

\section{DISCUSSION}

Our recorded descent and horizontal speeds (and their variability) for emperor penguins closely agree with previously published data, giving confidence in our extracted ascent speeds. Cruising speed has been estimated at about $2 \mathrm{~m} \mathrm{~s}^{-1}$ (Culik et al.1994, Wilson 1995), which is similar to our observed descending and horizontal speeds $\left(1.9 \mathrm{~m} \mathrm{~s}^{-1}\right.$ and $1.7 \mathrm{~m} \mathrm{~s}^{-1}$ respectively). Kooyman et al. (1992) recorded $2.8 \mathrm{~m} \mathrm{~s}^{-1}$ from penguins swimming horizontally beneath solid ice between air holes-which constrained situation may have stimulated slightly elevated swimming speeds; Sato et al. (2005) have more recently recorded $1.7 \mathrm{~m}$ $\mathrm{s}^{-1}$. Given the fact that none of the filmed material inspected in our study, collected from hundreds of penguins, showed animals moving upwards at high speed without bubble trails, we strongly suspect that our measured upward speeds (mean $5.3 \mathrm{~m} \mathrm{~s}^{-1}$ ) represent the maximum speeds of which emperor penguins are capable. Our estimated speeds are certainly the highest recorded in scientific studies. Compared with a penguin cruising speed of $2 \mathrm{~m} \mathrm{~s}^{-1}$, drag would be increased about 5.8-fold at the observed mean ascent speed of $5.3 \mathrm{~m} \mathrm{~s}^{-1}$, given no mechanism to reduce it (Eq. 2). Clearly, drag reduction will be advantageous provided that the energetic cost of doing so is not prohibitive. Our observations and analysis unequivocally demonstrate that emperor penguins ascending rapidly in the water column to jump onto ice shelves emit bubble clouds into the turbulent boundary layer over most of the body surface throughout their ascent. Emission does not diminish as a penguin approaches the surface, but increases. Because the bubbles are produced over most of the body surface, their drag-reducing function should exceed the performance of marine engineering plate/ship models described so far, in which maintaining sufficient bubble coverage within the turbulent boundary layer is a major problem. Moreover, penguin plumage is water-repellent (due to application of preen oil), so it is feasible that thin air films may form over the feather surfaces, as shown for 
water-repellent paints by Fukuda et al. (2000), promoting drag-reduction still further.

Penguin plumage can contain considerable quantities of air (Yoda \& Ropert-Coudert 2004). Recent calculations suggest that as much as $96 \%$ of plumage volume is occupied by air (Du et al. 2007), and during a dive the volume of trapped air will decrease according to Eq. (3), whence shrinkage decelerates with increasing depth. At a depth of $15 \mathrm{~m}$, air in the plumage will be compressed to $40 \%$ of its initial volume (and to $33 \%$ at $20 \mathrm{~m}$ ). We believe that emperor penguins essentially 'lock' the reduced plumage air volume at a depth of 15 to $20 \mathrm{~m}$. When they swim rapidly towards the surface, from about $60 \%$ (strategy 1 ) to $90 \%$ (strategy 2) of the initial volume is available to diffuse out through the fine plumage meshwork in the form of small bubbles that progressively coalesce along the body surface as the penguins ascend. At present we favour strategy (2) because of the observed persistence of bubbly wake formation right to the surface. Because of the characteristics of the depth:volume relationship, the expansion rate of the trapped air will be greater as the penguin approaches the sea surface (Fig. 4), thus maintaining release of air, even though the mass of trapped air is decreasing. Our model of compressed air storage is supported by observations of penguins that abort their ascent; on aborting, a penguin re-dives and bubbles soon stop issuing from the plumage, so the penguin and its 'track' become separated as the air in the plumage is repressurized. We do not know whether penguins that have aborted dives need to return to the surface to recharge the plumage with air, or still retain enough plumage air to try jumping again. Loading the plumage with air will increase penguin buoyancy, thus imposing an additional energetic cost as the birds swim downwards from the surface. The buoyancy force decreases approximately by a factor of 2.5 when diving from the free surface to a depth of $15 \mathrm{~m}$, so opposing buoyancy becomes easier as the penguins dive. On the other hand, our calculations indicate that buoyancy force, though non-negligible, can play only a small part in enhancing ascent speed.

For the proposed mechanism of air lubrication to work, emperor penguins need to have considerable control over their plumage. There is good evidence that this control exists. Penguin plumage is unlike that of other birds. First, feathers are present over the entire body surface rather than being present in tracts as in most other bird species (Stettenheim 2000). Secondly, each feather has 2 parts, an anterior flattened, pennaceous part that provides the smooth, waterproof (and water-repellent) outer coating of the penguin body surface, and a posterior down-like after-feather that provides insulation (Dawson et al. 1999). Erection and depression of the pennaceous part are both under muscular control (Kooyman et al. 1976; Dawson et al. 1999). On long foraging dives, it is believed that emperor penguins compress their plumage to expel air, thereby reducing drag (Kooyman et al. 1976) and the positive buoyancy that is undesirable in diving birds (Wilson et al. 1992). Hence 'locking' of a fixed volume of air by muscle action is entirely feasible. Fast water flow will also help to flatten the pennaceous part, squashing the after-feather beneath, in turn helping to keep air volume steady during ascents. Positive control by feather depression may play a part in forcing out air during the ascent, as suggested by strategy (2).

How much does air lubrication enhance speed in fast ascents? This question cannot be answered with precision from our observations since all penguins produced bubble clouds when ascending (i.e. none was without the air lubrication, so there were no 'controls'). Though the values for ascent speeds recorded in our study considerably exceed the accepted cruising speed ( 2 $\mathrm{m}$ $\mathrm{s}^{-1}$ ) for all penguin species (Culik et al.1994, Wilson 1995), some of the extra swimming speed will undoubtedly be due to enhanced flipper action (by some combination of increased flipper beat frequency or increased angle of incidence of flipper to water flow direction) underpinned by anaerobic 'sprint' muscle action. Interestingly, our ascent speed values (mean $5.3 \mathrm{~m} \mathrm{~s}^{-1}$, but occasionally as high as $8.2 \mathrm{~m} \mathrm{~s}^{-1}$ ) are much higher (by about 90\%) than those recorded $\left(2.8 \mathrm{~m} \mathrm{~s}^{-1}\right)$ in a recent study of emperor penguins jumping to far more modest heights $(<0.45 \mathrm{~m})$ through ice holes $1.2 \mathrm{~m}$ in diameter (Sato et al. 2005). Sato et al. (2005) do not mention the occurrence of bubbly wakes, and $2.8 \mathrm{~m} \mathrm{~s}^{-1}$ is identical with the horizontal under-ice speeds reported earlier by Kooyman et al. (1992). Given the variability of the observed ascent and emergence speeds, it is clear that emperor penguins can modulate speed and emergence angle considerably, as do Adélie penguins (Yoda \& Ropert-Coudert 2004).

The lack of 'controls' for the observed bubbly wake ascents means that our air-lubrication hypothesis for attainment of maximal emperor penguin speeds can only be considered as highly viable at this stage. The only method of confirming the hypothesis fully would seem to involve the construction and testing of a penguin replica that could be towed whilst emitting bubbles. This would be a technically difficult task as the complexity of penguin plumage would be difficult to replicate in a man-made porous membrane or mesh. However, this approach would appear to be more fruitful than any attempt (probably unethical) to constrain emperor penguins to ascend rapidly without air emission.

Our study only considers the emperor penguin. Since the plumage structure and control are similar in all penguin species (Dawson et al. 1999), the air lubrica- 
tion ascent-adaptation may be more general amongst the family Spheniscidae. Adélie penguins in particular may repay investigation as they leap to heights of 2 to $3 \mathrm{~m}$ above sea level (Yoda \& Ropert-Coudert 2004), yet cruise at $2 \mathrm{~m} \mathrm{~s}^{-1}$ (Sato et al. 2002).

Throughout our study we have assumed that the adaptive value of air lubrication lies in enhanced swimming speed and hence more effective jumps out of water. There may be additional benefits; it has recently been reported that air lubrication reduces the acoustic signal of ships (Matveev 2005). If this also applies to ascending emperor penguins, it may make them less detectable by predators that hunt by echolocation (e.g. killer whales).

Acknowledgements. The authors thank the BBC Natural History Unit for permission to use the Blue Planet video grabs and sequences presented, plus the supply of unpublished film. We thank the research scientists led by Prof G. Kooyman who facilitated making of the relevant section of the Blue Planet film. We particularly thank the photographer Doug Allen. We also thank Nick Crane for discussion.

\section{LITERATURE CITED}

Au D, Weihs D (1980) At high speeds dolphins save energy by leaping. Nature 284:548-550

BBC (2001) Blue Planet Programme 4, Frozen Seas. BBC Worldwide, London (video film)

Culik B, Wilson RP, Bannasch R (1994) Underwater swimming at low energetic cost by pygoscelid penguins. J Exp Biol 197:65-78

Davenport J (1994) How and why do flying fish fly? Rev Fish Biol Fish 4:184-214

Dawson C, Vincent JFV, Jeronimidis G, Rice G, Forshaw P (1999) Heat transfer through penguin feathers. J Theor Biol 199:291-295

Du N, Fan J, Wu H, Chen S, Liu Y (2007) An improved model of heat transfer through penguin feathers and down. J Theor Biol 248:727-735

Fukuda K, Tokunaga J, Nobunaga T, Nakatani T, Iwasaki T, Kunitake Y (2000) Frictional drag reduction with air lubricant over a super-water-repellent surface. J Mar Sci Technol 5:123-130

Guin MM, Kato H, Yamaguchi H, Maeda M, Miyanaga M (1996) Reduction of skin friction by microbubbles and its relationship with near-wall bubble concentration in a channel. J Mar Sci Technol 1:241-254

Submitted: June 30, 2010; Accepted: October 11, 2010
Hirata K, Kawai S (2001) Hydrodynamic performance of stream-lined body. National Maritime Research Institute, Tokyo, available at www.nmri.go.jp/eng/khirata/ fish/experiment/upf2001/body_e.html

Hooker SK, Miller PJO, Johnson MP, Cox OP, Boyd IL (2005) Ascent exhalations of Antarctic fur seals: a behavioural adaptation for breath-hold diving. Proc Biol Sci 272: 355-363

Kooyman GL, Drabek CM, Elsner R, Campbell WB (1971) Diving behaviour of the emperor penguin Aptenodytes forsteri. Auk 88:775-795

Kooyman GL, Gentry RL, Bergman WP, Hammel HT (1976) Heat loss in penguins during immersion and compression. Comp Biochem Physiol 54:75-80

Kooyman GL, Ponganis PJ, Catellini MA, Ponganis EP and others (1992) Heart rates and swim speeds of emperor penguins diving under sea ice. J Exp Biol 165:161-180

> Madavan NK, Deutsch S, Merkle CL (1985) Measurements of local skin friction in a microbubble-modified turbulent boundary layer. J Fluid Mech 156:237-256

Matveev KI (2003) Air cavity ships are ready for a wider market. Speed at Sea 9:13-16

Matveev KI (2005) Effect of drag-reducing air lubrication on underwater noise radiation from a ship hull. J Vib Acoust 127:420-422

McCormick ME, Bhattacharryya R (1973) Drag reduction of a submersible hull by electrolysis. Nav Eng J 85:11-16

- Sanders WC, Winkel ES, Dowling DR, Perlin M, Ceccio SL (2006) Bubble friction drag reduction in a high-Reynoldsnumber flat-plate turbulent boundary layer. J Fluid Mech 552:353-380

Sato K, Naito Y, Kato A, Niizuma Y and others (2002) Buoyancy and maximal diving depth in penguins: Do they control inhaling air volume? J Exp Biol 205:1189-1197

Sato K, Ponganis PJ, Habara Y, Naito Y (2005) Emperor penguins adjust swim speed according to the above-water height of ice holes through which they exit. J Exp Biol 208:2549-2554

Schlichting H (1968) Boundary layer theory, 6th edn. McGrawHill, New York, NY

Stettenheim PR (2000) The integumentary morphology of modern birds - an overview. Am Zool 40:461-477

> Weihs D (2002) Dynamics of dolphin porpoising revisited. Integr Comp Biol 42:1071-1078

Wilson RP (1995) Foraging ecology. In: Williams TD (ed) The penguins: Spheniscidae. Oxford University Press, Oxford, p 81-106

> Wilson RP, Hustler K, Ryan PG, Burger AE, Noldeke EC (1992) Diving birds in cold water: Do Archimedes and Boyle determine energetic costs? Am Nat 140:179-200

Yoda K, Ropert-Coudert Y (2004) Decision-rules for leaping Adélie penguins (Pygoscelis adeliae). J Zool (Lond) 263: $1-5$

Proofs received from author(s): January 23, 2011 